\title{
Tail-end Hg capture on Au/carbon-monoliths regenerable sorbents
}

M. Teresa Izquierdo ${ }^{1 *}$, Diego Ballestero ${ }^{2}$, Roberto Juan ${ }^{1}$, Enrique García-Díez, Begoña

Rubio', Carmen Ruiz'1, M. Rosa Pino ${ }^{2}$

${ }^{1}$ Instituto de Carboquímica, CSIC. c/Miguel Luesma, 4. 50018 Zaragoza. Spain.

${ }^{2}$ Instituto de Medioambiente. Universidad San Jorge. Autovía A23 Zaragoza-Huesca km 510.

50830 Villanueva de Gállego, Zaragoza. Spain.

*Corresponding author:

María Teresa Izquierdo

Tel. +34976733977

Fax. +34976733318

e-mail. mizq@icb.csic.es 


\section{ABSTRACT}

In this work, a regenerable sorbent for $\mathrm{Hg}$ retention based on carbon supported $\mathrm{Au}$ nanoparticles has been developed and tested. Honeycomb structures were chosen in order to avoid pressure drop and particle entrainment in a fixed bed. Carbon-based supports were selected in order to easily modify the surface chemistry to favour the Au dispersion. Results of $\mathrm{Hg}$ retention and regeneration were obtained in a bench scale experimental installation working at high space velocities (for sorbent; $53000 \mathrm{~h}^{-1}$; for active phase $2.610^{8} \mathrm{~h}^{-1}$ ), $120^{\circ} \mathrm{C}$ for retention temperature and $\mathrm{Hg}$ inlet concentration of $23 \mathrm{ppbv}$.

Gold nanoparticles were shown to be the active phase for mercury capture through an amalgamating mechanism. The mercury captured by the spent sorbent can be easily released to be disposed or reused. Mercury evolution from spent sorbents was followed by TPD experiments showing that the sorbent can be regenerated at temperatures as low as $220^{\circ} \mathrm{C}$.

KEYWORDS: Hg capture; regenerable sorbent; $\mathrm{Au} / \mathrm{C}$ sorbent; 


\section{INTRODUCTION}

The largest anthropogenic source of mercury to the atmosphere in the world is the burning of fossil fuels, primarily coal. Electrical power plants are estimated to account for about $25 \%$ of the global anthropogenic mercury emissions to the atmosphere and industrial and residential heating for another $20 \%$ [1].

In 2005 the USA Environmental Protection Agency (EPA) established "The Clean Air Mercury Rule" turning the United States into the first country to regulate these emissions. On the other hand, the European Commission published in 2005 the "Community Strategy Concerning Mercury", which identifies coal combustion as one of the main sources of anthropogenic mercury also in Europe. According to the European Environmental Agency (EEA), Spain is the third country among EU27 in mercury emissions, mainly due to coalfired plants [2].

Mercury is found in coal in the form of sulphides or associated to them, interchanged on clays and associated to the organic matter in low rank coals. During the combustion processes, these forms evaporate, giving rise to $\mathrm{Hg}(0), \mathrm{HgO}$ and $\mathrm{HgCl}_{2}$, which proportions in gas phase depend on the concentration and mode of occurrence in the coal and on the compounds present in the gaseous stream, especially particulates and $\mathrm{HCl}$ [3]. In some cases, more than $90 \%$ of the $\mathrm{Hg}$ in coal can be emitted in gas phase through the stack.

Mercury can be removed from coal before combustion by coal cleaning, during combustion depending on unburned carbon, by existing air pollution control devices and with mercury specific control devices. Particulate matter control by ESP or FF control only particle-bound mercury and FGD units can only remove oxidized mercury. So, specific control processes for elemental mercury capture are now under research or demonstration.

The state of the art technology that has shown promise for controlling element as well as oxidized mercury is active carbon injection (ACI). A major problem associated with ACI 
technology is that the commercial value of fly ash is sacrificed due to its mixing with contaminated activated carbon powder. So, a system with two separate powder collectors and ACI between the first collector for fly ash and the second collector for activated carbon powder would be necessary. The forthcoming regulation concerning to $\mathrm{Hg}$ emissions in the UE and the limited residue production to be accomplished by any depuration technology, make the development of new processes mandatory. In addition, carbon filter beds present problems associated to the lower affinity between nontreated carbons (without specific active sites) and elemental mercury $[4,5]$ as well as pressure drop in the fixed bed. High efficiency sulphur doped carbons are used for $\mathrm{Hg}$ retention on fixed beds, but the problem of toxic wastes still remains.

Regenerable sorbents can accomplish high mercury retention that can be recovered as well as balance cost because of its regenerability. Recognizing reversible characteristics of mercury amalgamate with gold and silver, gold- or silver-coated silica beds have been widely used to pre-concentrate low concentration of elemental mercury for its detection [6, 7]. The gold- or silver-mercury amalgam is extremely stable at room temperature. However, the amalgam decomposes to release mercury to a gas phase at higher temperatures, leaving clean gold or silver surfaces ready for further mercury capture [7]. In order to effectively collect trace amounts of mercury, it is necessary to have the gold and/or silver in a form of large surface areas [8]. The gold and silver as monolayer is effective for mercury capture [9]. The challenge with this design is that with repetitive exposure to flue gases and heating, the coated gold or silver layer tends to aggregate into larger islands in micrometer sizes, which could lead to inefficient mercury capture $[7,8,10]$.

Despite the preconceived idea concerning Au gold price, it is a little less expensive than Pt, a very common catalyst used in several applications as fuel cells where Pt is used at high 
concentration. Moreover, it is expected that the spent $\mathrm{Au} / \mathrm{C}$ sorbent after several cycles of $\mathrm{Hg}$ retention-regeneration can be burned to recover gold, improving the economy of the process. Some tests of $\mathrm{Hg}$ capture and sorbent regeneration are found in the literature [7, 11]. However, both studies performed mercury adsorption at room temperatures much lower than coal-fired power plant flue gas temperatures or stack temperatures.

In this work, a study of $\mathrm{Hg}$ retention and regeneration on Au-based sorbents has been carried out. Au nanoparticles were deposited onto structured carbon monoliths by two different methodologies. These methodologies allow us to reach different Au concentrations on the sorbent surface and different Au particle size in order to initially screen the influence of these parameters on the $\mathrm{Hg}$ capture efficiency, as a preliminary study before to extent the research to flue gas real conditions.

The novelty of this work is focused on two aspects: the deposition of gold nanoparticles on carbon material, as it is stated in [12] and the $\mathrm{Au} / \mathrm{C}$ sorbents regenerability study after $\mathrm{Hg}$ retention, in order to achieve a waste free process (except $\mathrm{Hg}$ itself) for $\mathrm{Hg}$ capture.

\section{Experimental}

\subsection{Regenerable sorbents}

Honeycomb structured carbon monoliths were used as supports for $\mathrm{Au} / \mathrm{C}$ sorbents. Raw support (labelled MC-orig) has square channel with a density $69 \mathrm{cell} / \mathrm{cm}^{2}$.

Different treatments were applied to the raw support in order to modify the surface chemistry to improve further dispersion of gold nanoparticles. Raw supports were oxidized with either nitric acid (labelled MC-HNO3) or air (labelled MC-air). Raw supports were also steam activated (labelled MC-vapor). These procedures are described elsewhere [13]. 
Two different methods for gold deposition onto the supports have been used: colloidal method and salt method. In colloidal gold method (based on [14]), citrate anion acts as reducing agent of the gold salt and protector of the gold sol formed preventing its aggregation. The second method consists of the direct reduction of a gold salt by the own carbon material of the support (patent under processing). In both methods it is necessary to force the gold suspension/solution to pass through the channels of the monolithic support to achieve a homogeneous gold deposition along the channels of the monolithic supports. After gold deposition, a reducing treatment was applied to the sorbents. A gas mixture containing $4 \% \mathrm{H}_{2} / \mathrm{Ar}$ was passed through the sorbent at $300^{\circ} \mathrm{C}$ during $1 \mathrm{~h}$. Samples coming from gold salt deposition were labelled adding to the support label - $\mathrm{Au}-\mathrm{SHC}$ (for sorbent with high $\mathrm{Au}$ content on the surface) and -Au-SMC (for sorbent with medium Au content on the surface). Samples coming from the colloidal method were labelled adding to the support label $-\mathrm{Au}-\mathrm{C} 2$.

\subsection{Sorbents characterization}

Before gold deposition, supports were characterized by elemental analysis, $\mathrm{N}_{2}$ physisorption and thermal programmed desorption (TPD). After gold deposition, sorbents were characterized by scanning electron microscopy with energy-dispersive X-ray analyzing system (SEM-EDX), Field Emission SEM (FE-SEM) and N2 physisorption.

Surface areas were determined with $\mathrm{N}_{2}$ at $77 \mathrm{~K}$. The Brunauer-Emmett- Teller (BET) equation was applied to $\mathrm{N}_{2}$ adsorption isotherms. Prior each analysis, samples were outgassed at $150^{\circ} \mathrm{C}$ and up to a vacuum less than $10^{-5} \mathrm{~mm} \mathrm{Hg}$.

The TPD runs were carried out with a custom built set-up, consisting of a tubular quartz reactor placed inside an electrical furnace. TPD experiments were carried out by heating the 
samples up to $1100^{\circ} \mathrm{C}$ in $\mathrm{Ar}$ flow at a heating rate of $10^{\circ} \mathrm{C} / \mathrm{min}$, recording the $\mathrm{CO}$ and $\mathrm{CO}_{2}$ evolved at each temperature with a quadrupole mass spectrometer from Pfeiffer. The calibrations for $\mathrm{CO}$ and $\mathrm{CO}_{2}$ were carried out by standards diluted in Ar. In a typical run $0.5 \mathrm{~g}$ of carbon was placed in a horizontal quartz tube reactor under an Ar stream of $30 \mathrm{ml} / \mathrm{min}$. The study of the gold distribution along the monolith channels was carried out by SEM and the particle size distribution was determined by image analysis from electron micrographs obtained from FE-SEM.

\subsection{Mercury retention experiments}

A bench scale installation (Figure 1) was used to determine the sorbent efficiency for the capture of elemental mercury and the maximum retention capacity. This installation consists of flowmeters for nitrogen, a permeation tube for $\mathrm{Hg}(0)$ flow generation (inside a tube immersed in a thermostatic bath), a quartz reactor heated by a furnace and an on-line elemental mercury analyzer (VM3000). Moreover, the installation is provided with a tail-end train of flasks to allow the capture the mercury as well as its speciation (in the case of evidences of oxidation under the experimental conditions). The installation is built up with Teflon pipes and pieces (in the part of the installation where $\mathrm{Hg}$ is present) to prevent possible mercury attack to steel.

The Hg breakthrough curves were obtained at space velocity $53000 \mathrm{~h}^{-1}$ (considering the whole sorbent, and $2.610^{8} \mathrm{~h}^{-1}$ considering the active phase), $120^{\circ} \mathrm{C}$ (near the stack temperature) and $\mathrm{Hg}$ inlet concentration of $200 \mu \mathrm{g} / \mathrm{m}^{3}$ (23 ppb). The $\mathrm{Hg}(0)$ total amount retained was calculated from the integration of the breakthrough curve. Some experiments were repeated to test reproducibility. Moreover, some $\mathrm{Hg}$ exhausted sorbents were analyzed 
in a mercury analyzer (AMA) in order to corroborate results on $\mathrm{Hg}$ retention from breakthrough curves integration.

In order to test the best regeneration temperature, $\mathrm{Hg}$ temperature programmed desorption (Hg-TPD) of exhausted sorbents was performed on some selected samples. In order to evaluate the appropriate conditions for sorbent regeneration, mercury exhausted sorbent was heated up to $450^{\circ} \mathrm{C}$ with a heating rate of $10^{\circ} \mathrm{C} / \mathrm{min}$, and the $\mathrm{Hg}$ evolution was followed on line as a function of the temperature.

\section{Results and Discussion}

\subsection{Supports characterization}

Table 1 summarizes the results from supports characterization. As it can be observed from elemental analysis, the level for introduction of oxygen in the raw support structure (MCorig) is similar for acid-oxidation and steam activation treatments and lower for air-oxidation. As it can be deduced from Table 1, supports are mainly microporous. Steam activation develops the porous structure of the monoliths being surface area and pore volume are higher than that measured for raw support. Air oxidation of raw support does not alter significantly porous structure and surface area. However, acid oxidation alters the support porosity, decreasing the surface area as well as the total pore volume. It is generally reported that the liquid phase oxidation does not change significantly the texture of the activated carbons, although under more drastic conditions (concentrated acid, heating until complete evaporation) a decrease in the surface and pore volume has been observed [15] due to the collapse of pore walls. 
The conditions used to oxidize the raw support change the amount and type of surface oxygen functional groups present on the resulting supports. The amounts of $\mathrm{CO}$ and $\mathrm{CO}_{2}$ desorbed and the temperatures at which these gases released have been found to be characteristics of various oxygen functional groups. It has been proposed that $\mathrm{CO}_{2}$ derives from functional groups like carboxylic acids, anhydrides and lactones and $\mathrm{CO}$ derives from functional groups like phenolic and quinonic groups. Groups yielding $\mathrm{CO}_{2}$ have been shown to decompose typically over a range of temperatures $150^{\circ}-600^{\circ} \mathrm{C}$ while groups yielding $\mathrm{CO}$ decompose at temperatures in the range of $600^{\circ}-1000^{\circ} \mathrm{C}[16]$.

The total amount of $\mathrm{CO}$ and $\mathrm{CO}_{2}$ evolved up to $1100^{\circ} \mathrm{C}$ in a TPD run for each activated carbon is reported in Table 1. As it can be deduced, the three treatments (nitric acid, air or steam) increase the amount of total oxygen groups present in the supports. The introduction of CO-evolving groups is similar for the three supports; however, the introduction of $\mathrm{CO}_{2}$ evolving groups is much higher for support MC-HNO3. This fact is important to be considered, because it is reported that the deposition of some metals on carbon supports, in particular gold, seems to be favoured by carboxylic-type surface groups [17].

\subsection{Sorbents characterization}

Sorbents surface area does not vary significantly after gold deposition, as can be seen comparing supports and sorbents surface area values in Tables 1 and 2 . This fact is indicative of non-pore blockage due to Au nanoparticles deposition.

The study of the distribution of gold along the monolith channels was carried out by SEMEDX. Monoliths were longitudinal sectioned in order to determine the Au distribution along the channels. Appropriate homogeneity of Au content was found and no Au accumulation in the interaction of the channel and the wall of the monoliths was found. Table 2 shows the $\mathrm{Au}$ 
content on the surface for the sorbents. X-Ray photoelectron spectroscopy (XPS) confirmed that $\mathrm{Au}$ is in the metallic state and oxidized forms were not detected. It is important to note that the Au content reported in Table 2 is referred to Au surface content not to Au bulk content. The content of Au on the bulk sorbent was determined by ICP-OES and it was $0.11 \%$ for sorbent MC-orig-Au-SHC. Little research can be found in the literature concerning $\mathrm{Hg}$ capture by regenerable sorbents, some of them concerning $\mathrm{Ag}$ as active phase for $\mathrm{Hg}$ to be amalgamated. However in those research work [18-19], the Ag content (on bulk sorbent) was at least one order of magnitude higher than that used in this work (for sorbent with the highest amount of $\mathrm{Au}$ on the carbon surface).

Micrographs of the sorbents taken by FE-SEM in backscattering mode are shown in Figure 2. The images show, except for sorbent MC-orig-Au-SHC, that the particles are well separated and dispersed. The surface covered by $\mathrm{Au}$, the Au particle size distribution, the Au Feret average diameter as well as the circularity of the Au particles were obtained using Image Analysis software. Results of this analysis are reported on Table 2. For sorbent MCorig-Au-SHC only the fraction of surface covered by gold can be obtained; as it can be seen in Figure 2, Au particles are agglomerated, creating big and connected clusters, making impossible to calculate the particle diameter.

With the sodium citrate method to disperse $\mathrm{Au}$ nanoparticles onto the monoliths, the negatively-charged citrate ions are adsorbed onto the gold nanoparticles, introducing the surface charge that repels the particles and prevent them from aggregating. However, with the salt method there is a spontaneous gold particle formation onto the carbon material due to the reduction potential of the own carbon material to reduce $\mathrm{Au}(\mathrm{III})$. However, particle nucleation on carbon material is fast and ceases in a very short time, after which particle growth, rather than further nucleation, dominates. Therefore, the process needs a fine control 
to prevent the formation of gold aggregates. These two mechanisms can explain the differences in surface coverage as well as Au particle size reported in Table 2.

There is a straightforward correlation between Au surface coverage and the Au particle diameter, indicating the tendency of Au particles to be sintered when particles are close up enough. The amount of Au loaded on the support surface has a big influence on the $\mathrm{Au}$ particle diameter. When the surface fraction covered by Au is too high, the size of particle increases and this fact favors the sintering of the Au particles, reaching the formation of big clusters in the case of sorbent MC-orig-Au-SHC. However, there is not a direct correlation between the Au content on the surface and the particle size or surface coverage, but the trend is the higher Au content on the surface of the support, the higher Au particle size and surface coverage.

\subsection{Mercury retention-regeneration tests}

Blank experiments on the supports were carried out in order to test their influence on the retention capacity of the Au-based sorbents. These experiments were performed according to the conditions described in the experimental section.

Figure 3a depicts breakthrough curves for supports and the amount of $\mathrm{Hg}$ captured (from integration of the breakthrough curves, when reached 95\% saturation, deducting death volume of the reactor) is given in Table 3. As it can be seen, all the supports have some ability for $\mathrm{Hg}$ retention, in particular, the support treated with nitric acid, MC-HNO3. However, these supports cannot be considered for real blank experiments. The reason is that once $\mathrm{Au}$ is deposited, a reducing treatment is applied to the sorbents, so the real blank is a support that undergoes the same reducing treatment. Thus, reduced supports (labelled as - 
red) at the same reducing conditions than that undergone by the sorbents were tested for $\mathrm{Hg}$ retention capacity.

Figure $3 \mathrm{~b}$ depicts $\mathrm{Hg}$ breakthrough curves for reduced supports and the amount of $\mathrm{Hg}$ captured is given in Table 3 . As it can be seen, the saturation time is in the range of few minutes and the amount of $\mathrm{Hg}$ captured is negligible, except for support MC-HNO3-red. The behaviour of the support treated with nitric acid (as prepared and reduced) can be explained in terms of surface chemistry of this support. As it can be deduced from Table 1, this support has incorporated a high amount of $\mathrm{CO}_{2}$-evolving groups, which could chemisorb Hg. Once the support has been reduced, part of these groups disappears and less active sites for $\mathrm{Hg}$ chemisorption are available. However, after reduction, this support presents still some $\mathrm{Hg}$ retention capacity (higher than the other reduced supports). This fact can be explained in terms of the temperature during reduction treatment. The reduction of support MC-HNO3 was carried out at $300^{\circ} \mathrm{C}$ and the appropriate temperature to remove most of the $\mathrm{CO}_{2}$ evolving groups is around $400^{\circ} \mathrm{C}$. In order to check this hypothesis, MC-HNO3 exhausted support was undergone to a TPD to follow the evolution on the Hg adsorbed onto the support. Figure 4 shows the Hg-TPD curve in which two peaks can be observed. First peak appears at $220^{\circ} \mathrm{C}$ and can be attributed to $\mathrm{Hg}$ retained through physisorption mechanism. Second peak appears at $430^{\circ} \mathrm{C}$ and can be attributed to $\mathrm{Hg}$ retained through chemisorption mechanism onto $\mathrm{CO}_{2}$-evolving groups, which are removed completely near $550^{\circ} \mathrm{C}$. After $\mathrm{Hg} \mathrm{TPD}$ experiment, a breakthrough curve for $\mathrm{Hg}$ was obtained for the regenerated support (MC-HNO3-reg), resulting in a negligible retention of $\mathrm{Hg}$, since Table 3, obtaining similar values of $\mathrm{Hg}$ retention capacity than those obtained for the rest of the supports once reduced.

These results agree with those reported in the literature concerning with the low affinity between non-treated activated carbons (without specific active sites) and elemental mercury $[4,5]$. Both studies conclude that it is needed heterogeneous oxidation with subsequent 
binding on the surface to retain the $\mathrm{Hg}$. In the case of treated carbon sorbents, mercury retention is predicted to occur entirely by chemisorption.

Figure 5 depicts the breakthrough curves for the $\mathrm{Au} / \mathrm{C}$ sorbents and Table 3 summarizes the total amount of $\mathrm{Hg}$ retained on the sorbents (calculated from the integration of the breakthrough curves, when reached 95\% saturation, deducting death volume of the reactor and the contribution of the supports). First noticeable observation is the reproducibility of the experiments, taken into account that the inlet $\mathrm{Hg}$ concentration is as low as 23 ppbv (200 $\mu \mathrm{g} / \mathrm{m}^{3}$ ). Because of the on-line mercury analyzer only determines the concentration of elemental mercury present in the gas, in some of the duplicated experiments the possible oxidation of elemental mercury by Au catalytic oxidation was followed. The train of flasks containing a chilled solution of $\mathrm{KMnO}_{4} / \mathrm{H}_{2} \mathrm{SO}_{4}$ and chilled solution of $\mathrm{KCl}$ was placed after the mercury analyzer in order to retain elemental and oxidized mercury, respectively (the socalled Ontario-Hydro ASTM method). Both solutions were further analyzed by cold-vapor atomic absorption. No oxidized mercury was detected in none of the flasks analyzed. Thus, all the mercury is in the form of $\operatorname{Hg}(0)$ that can amalgamate. However, the presence of $\mathrm{SO}_{2}$ and NO in the flue gas could contribute to catalyze mercury oxidation in the presence of $\mathrm{Au}$ nanoparticles; so ongoing work is being carried out on this topic.

Because of the time needed to reach the same level of saturation is different for each sorbent, Table 3 also reports the efficiency of $\mathrm{Hg}$ retention calculated as the ratio between the amount of $\mathrm{Hg}$ retained by the sorbents at $30 \%$ of saturation and the total amount of $\mathrm{Hg}$ feeded into the reaction during this time. The value of $30 \%$ of saturation was chosen considering that in real application the saturation or near the saturation of the sorbents are never reached.

The distinct difference in mercury capture by the supports and the sorbents demonstrates the decisive role of $\mathrm{Au}$ nanoparticles deposited onto the carbon monoliths for mercury capture. Thus, it can be said that the mercury capture on the $\mathrm{Au} / \mathrm{C}$ sorbents is based on the amalgam 
mechanism. Similar findings are reported on the literature with Au or Ag supported on other carbon materials [20].

As it can be deduced from Table 3 there is not a direct relationship between Au content and either $\mathrm{Hg}$ capture capacity of the sorbents at the same level of saturation or capture efficiency. This fact means that not all the Au deposited on the supports is efficient for $\mathrm{Hg}$ capture. There are overwhelming evidences concerning the size dependence on chemical reactivity. Smaller particles have large number of atoms at the surface [21-23]. These atoms differ from atoms in the bulk of the crystal in the way that they have an incomplete set of nearest neighbours (i.e. coordination number). Thus, a small Au nanocrystal of $1 \mathrm{~nm}$ diameter would have near $100 \%$ of its atoms on the surface and at increasing diameter the amount of atoms on the surface would be decreased. Although those studies were related to catalytic applications of $\mathrm{Au}$ nanoparticles, some work can be found related to the influence of the $\mathrm{Au}$ surface morphology at the nanometer scale and the role of active sites on $\mathrm{Hg} / \mathrm{Au}$ amalgam formation [24].

According to those findings, in the present case the Au nanoparticles size has a big influence on the $\mathrm{Hg}$ capture efficiency, as it can be seen in Figure 6. Despite not being possible to calculate $\mathrm{Au}$ particle size of sorbent $\mathrm{MC}$-orig-Au-SHC, its efficiency for mercury retention has been added into this Figure, out of scale, only for comparison purpose. It is clearly seemed that there is a compromise between the Au amount on the surface and the particle size reached. So, efforts have to be focused on the development of a sorbent with higher $\mathrm{Au}$ content on the carbon surface and an appropriate Au particle size.

Exhausted sorbents were undergone to a Hg-TPD to follow the evolution of the $\mathrm{Hg}$ adsorbed onto the sorbents in order to study the release temperature for mercury amalgamated in order to obtain the appropriate temperature for sorbent regeneration. Figure 4 shows Hg-TPD curves for some sorbents. The captured mercury started to release at $100^{\circ} \mathrm{C}$, reaching the 
maximum around $220^{\circ} \mathrm{C}$. At $275^{\circ} \mathrm{C}$, approximately the $90 \%$ of the captured mercury has been evolved. These results suggest that the appropriate temperature for sorbent regeneration is slightly higher than $200^{\circ} \mathrm{C}$. This temperature is lower than that used to prepare the sorbent as it is described in the Experimental section. This fact leads to consider that under this temperature and atmosphere the nanoparticles are not expected to undergo sintering. However, the removal of mercury from the gold crystal lattice could affect the point defects of the lattice [23] and thus the following step of mercury capture onto the regenerated sorbent. This aspect should be carefully studied, but in this case we are limited by the amount of Au deposited ( $0.1 \%$ in the best case), which conditions the available techniques to study the regenerated sorbents because of their detection limits.

The mechanism for $\mathrm{Hg}$ retention onto the sorbents is different from that showed for support MC-HNO3 as it can be deduced from Figure 4. The chemisorption mechanism is very limited after removing $\mathrm{CO}_{2}$-evolving groups (sorbents have all been reduced at $300^{\circ} \mathrm{C}$ in $\mathrm{H}_{2}$ atmosphere) from supports, as it can be deduced from the total amount of $\mathrm{Hg}$ captured given in Table 3. So, the mechanism for $\mathrm{Hg}$ retention could be attributable to the amalgamation with Au nanoparticles also for sample MC-HNO3-Au-C2. This fact is very significant, because temperatures for sorbent regeneration are lower than for support $\mathrm{MC}-\mathrm{HNO} 3$ and do not depend on the surface chemistry of the sorbents. However, a small tail for mercury evolution is found at higher temperature, suggesting that some mercury is still retained on the sorbent; this fact could be indicative of some $\mathrm{Hg}$ chemisorption on the support, corresponding to the activity exhibited by supports and reported in Table 3. In order to completely remove all the $\mathrm{Hg}$ from the sorbents, regeneration temperature should be increased, reducing the advantage of the economy of low temperature regeneration. On the other hand, the nonreleased mercury should be a constant along capture-regeneration cycles and this fact should 
not modify $\mathrm{Hg}$ capture after the first regeneration cycle. Further work will be directed to investigate this hypothesis.

\section{CONCLUSIONS}

Regenerable sorbents based on Au deposition on structured carbon-based monoliths has been developed and tested to determine their Hg capture capacity as well as their regenerability. Sorbents with Au bulk content lower than $0.1 \%$ can retain near $30 \mathrm{mg} \mathrm{Hg} / \mathrm{g} \mathrm{Au}$, exhibiting a high efficiency for mercury capture. However, the $\mathrm{Hg}$ capture capacity of sorbents is not directly related to the amount of Au supported. The most important factor determining elemental mercury retention seems to be the gold nanoparticle size and a balance between the amount of Au supported and the nanoparticle size should be found.

The regeneration of the $\mathrm{Hg}$ exhausted sorbent can be carried out at low temperature if the absence of $\mathrm{CO}_{2}$-evolving groups (from TPD) is guaranteed, in order to avoid $\mathrm{Hg}$ chemisorption on carbon support.

\section{Acknowledgements}

The financial support from Spanish Ministry of Science and Innovation (ref: CTQ200806860-C02-02/PPQ) is duly recognized. Authors want to thank Susana Cortés for CVAA mercury analysis.

\section{References}


[1] The Global Atmospheric Mercury Assessment: Sources, Emissions and Transport. UNEP Chemical Branch, UNEP-Chemicals, Geneva, 2008.

[2] European Union emission inventory report 1990-2008 under the UNECE Convention on Long-range Transboundary Air Pollution (LRTAP). EEA Technical Report 7/2010. Copenhagen, 2010.

[3] E.S. Olson, B.A. Mibeck, Oxidation Kinetics and the Model for Mercury Capture on Carbon in Flue Gas, International Conference on Air Quality V, Arlington, VA, September 19-21, 2005.

[4] F.E. Huggins, N. Yapa, G.P Hyffman, C.L. Senior, XAFS characterization of mercury captured from combustion gases on sorbents at low temperature, Fuel Proc. Tech. 82 (2003) 167-196.

[5] B. Padak, J. Wilcox, Understanding mercury binding on activated carbon, Carbon 47 (2009) 2855-2864.

[6] S.J. Long, D.R. Scott, R.J. Thompson, Atomic absorption determination of elemental mercury collected from ambient air on silver wool, Anal. Chem. 45 (1973) 2227-2233.

[7] R. Nowakowski, T. Kobiela, Z. Wolfram, R. Duoes, Atomic force microscopy of $\mathrm{Au} / \mathrm{Hg}$ alloy formation on thin Au films, Applied Surface Science 115 (1997) 217-231.

[8] F.H. Schaedlich, D.R. Schneeberger, Cartridge for Collection of a Sample by Adsorption onto a Solid Surface, U.S. Patent 5660795, 1997.

[9] M. Levlin, E. Ikävalko, T. Laitinen, Adsorption of mercury on gold and silver surfaces, J. Anal. Chem. 365 (1999) 577-586.

[10] C. Battistoni, E. Bemporad, A. Galdikas, S. Kaciulis, G. Mattogno, S. Mickevicius, V. Olevano, Interaction of mercury vapour with thin films of gold, Appl. Surf. Scie. 103 (1996) 107-111. 
[11] T.Y. Yan, A novel process for Hg removal from gases, Ind. Eng. Chem. Res. 33 (1994) $3010-3014$.

[12] Highlights from recent literature. Gold Bull. 43 (2010) 66-74.

[13] R. Juan, M.T. Izquierdo, C. Ruiz, B. Rubio, Preparation and Characterization of Carbon-Based Regenerable Sorbents for Mercury Retention. Carbon'2009. Internacional Conference on Carbon. Biarritz, France, 2009.

[14] J. Turkevich, P.C. Stevenson, J. Hillier, A study of the nucleation and growth processes in the synthesis of colloidal gold, Discuss. Far. Soc. 11 (1951) 55-75.

[15] J.S. Noh, J.A. Schwarz, Effect of $\mathrm{HNO}_{3}$ treatment on the surface-acidity of activated carbons, Carbon 28 (1990) 675-682.

[16] R.C. Bansal, J.B. Donnet, F. Stoeckli, Active Carbon. Marcel Dekker. New York 1988.

[17] L. Jiang, L. Gao, Modified carbon nanotubes: an effective way to selective attachment of gold nanoparticles, Carbon 41 (2003), 2923-2929.

[18] Y. Liu, D.J.A. Kelly, H. Yang, C.C.H. Lin, S.M. Kuznicki, Z. Xu, Novel regenerable sorbent for mercury capture form flue gases of coal-fired power plant, Environ. Sci. \& Tech. 42 (2008) 6205-6210.

[19] J. Dong, Z. Xu, S.M. Kuznicki, Mercury removal from flue gases by novel regenerable magnetic nanocomposite sorbents, Environ. Sci. \& Tech. 43 (2009) 3266-3271.

[20] G. Luo, H. Yao, M. Xu, X. Cui, W. Chen, R. Gupta, Z. Xu, Z. Carbon nanotube-silver composite for mercury capure and analysis, Energy \& Fuels 24 (2010) 419-426.

[21] M. Haruta, Size- and support-dependency in catalysis of gold, Catal. Today 36 (1997) 153-166.

[22] M. Haruta, Gold as a Novel Catalyst in the $21^{\text {st }}$ Century: Preparation, Working Mechanism and Applications, Gold Bull. 37 (2004) 27-36. 
[23] S. Schimpf, M. Lucas, C. Mohr, U. Rodemerck, A. Bruckner, J. Radnik, H. Hofmeister, P. Claus, Supported gold nanoparticles: in-depth catalyst characterization and application in hydrogenation and oxidation reactions, Catal. Today 72 (2002) 63-78.

[24] R. Nowakowski, T. Kobiela, Z. Wolfram, R. Dus, Atomic force microscopy of Au/Hg alloy formation on thin Au films, Appl. Surf. Sci. 115 (1997) 217-231.

\section{TABLE CAPTIONS}

Table 1. Supports characteristics

Table 2. Sorbents characteristics

Table 3. $\mathrm{Hg}$ retention capacity of supports and sorbents. 


\section{FIGURE CAPTIONS}

Figure 1. Experimental installation for $\mathrm{Hg}$ retention_tests.

Figure 2. Fe-SEM micrographs of the sorbents, Au particle size distribution and circularity of the Au particles : a) MC-orig-Au-HC; b) MC-orig-Au-SMC; c) MC-orig-Au-C2; d) MCHNO3-Au-C2; e) MC-air-Au-C2; f) MC-vapor-Au-C2.

Figure 3. Mercury breakthrough curves for the supports. a) 1: MC-HNO3; 2: MC-vapor; 3: MC-air; 4: MC-orig. b) 1: MC-HNO3-red; 2: MC-vapor-red; 3: MC-air-red; 4: MC-orig-red. 
Figure 4. Measured outlet $\mathrm{Hg}$ concentration in temperature programmed desorption for exhausted support 1:MC-HNO3 and for exhausted sorbents 2: MC-orig-Au-SHC; 3: MCorig-Au-SMC ; 4: MC-HNO3-Au-C2.

Figure 5. Mercury breakthrough curves for the sorbents. 1: MC-orig-Au-SHC-1; 2: MC-origAu-SHC-2 ; 3: MC-orig-Au-SMC ; 4: MC-HNO3-Au-C2; 5: MC-orig-Au-C2; 6: MC-vapor$\mathrm{C} 2$.

Figure 6. Relationship between $\mathrm{Hg}$ captured by the sorbents and the amount of Au and its particle size (amount of $\mathrm{Hg}$ captured at 95\% saturation; efficiency at 30\% saturation). 